\title{
Inside the World Bank's Black Box Allocation System: How Well Does IDA Allocate Resources to the Neediest and Most Vulnerable Countries?
}

\section{Benjamin Leo}

\section{Abstract}

During the last few International Development Association (IDA) replenishment negotiations, several large donors have pressed for reforms to further increase the share of IDA resources provided to the neediest and most vulnerable countries. While the proposed reforms take different forms, the philosophical thrust is the same-push IDA's focus further down the development chain. Against this backdrop, this paper explores just how well IDA's existing performance-based allocation (PBA) system actually addresses these issues. To achieve this, I examine how IDA allocations are distributed at each successive stage of the PBA methodology based upon a number of need and vulnerability measures. Next, I apply two simple measures to gauge IDA's performance: (1) whether per-capita allocations to the neediest and most vulnerable countries are equal to or greater than those for the best off countries and (2) whether allocations to the neediest and most vulnerable countries increase between the baseline and final allocation scenarios. Based on these criteria, IDA has a mixed track record. IDA's performance is very modest with respect to the relative share allocated to the neediest or most vulnerable countries. Of the eight measures examined, only two illustrate parity between final allocations to the bottom and top quartile of countries. However, the litany of PBA exceptions clearly helps to redistribute resources in absolute terms. Per-capita allocations to the neediest and most vulnerable countries more than doubles between the baseline and final PBA scenarios for every need and vulnerability indicator examined. Clearly, the existing system has several built-in biases to redistribute resources to these countries. However, these exceptions fall short from ensuring full parity that some IDA donors may wish to achieve. As such, the philosophical debate among key IDA donors likely will continue for the foreseeable future.
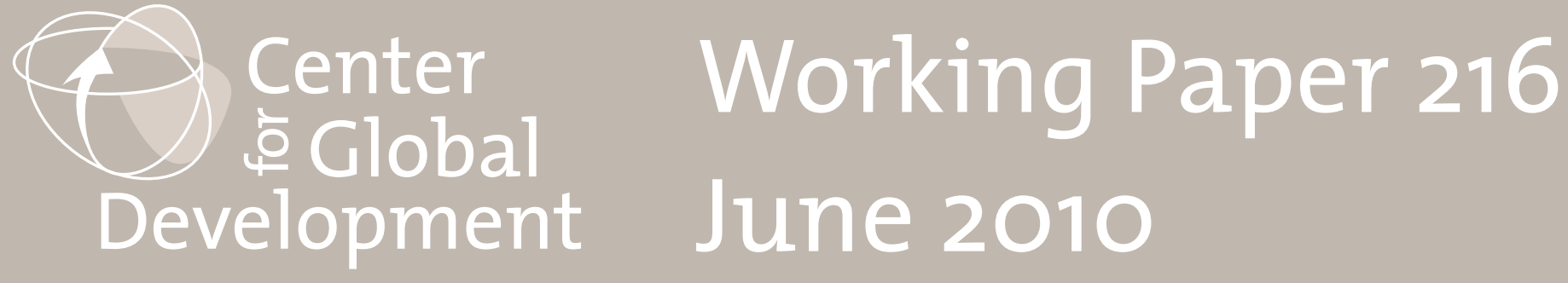


\title{
Inside the World Bank's Black Box Allocation System: How Well Does IDA Allocate Resources to the Neediest and Most Vulnerable Countries?
}

\author{
Benjamin Leo \\ Center for Global Development
}

Benjamin Leo is a research fellow at the Center for Global Development and former director for African Affairs at the National Security Council and senior staff member of the U.S. Department of Treasury. The author thanks Julia Barmeier for her tireless and professional work to create the development needs and economic vulnerability datasets. He also thanks Ravi Kanbur, Alan Gelb, Charles Kenny, and several anonymous reviewers for input and comments on earlier drafts of this paper. The author is solely responsible for any errors in fact or judgment.

CGD is grateful for contributions from the Norwegian Ministry of Foreign Affairs and the Swedish Ministry of Foreign Affairs in support of this work.

Benjamin Leo. 2010. "Inside the World Bank's Black Box Allocation System: How Well Does IDA Allocate Resources to the Neediest and Most Vulnerable Countries?" CGD Working Paper 216. Washington, D.C.: Center for Global Development. http://www.cgdev.org/content/publications/detail/1424248

Center for Global Development 1800 Massachusetts Ave., NW Washington, DC 20036

202.416.4000

(f) 202.416 .4050

www.cgdev.org
The Center for Global Development is an independent, nonprofit policy research organization dedicated to reducing global poverty and inequality and to making globalization work for the poor. Use and dissemination of this Working Paper is encouraged; however, reproduced copies may not be used for commercial purposes. Further usage is permitted under the terms of the Creative Commons License.

The views expressed in this paper are those of the author and should not be attributed to the board of directors or funders of the Center for Global Development. 


\section{OVERVIEW}

Over the last few International Development Association (IDA) replenishment periods, several large donors have pressed for reforms to the way that IDA allocates its scarce development resources. These negotiating efforts have taken several forms. Some donors, such as the United Kingdom, have advocated a decrease in the relative weight given to governance measures (ex corruption and public administration quality) or larger performance-based allocation (PBA) system exceptions for fragile or vulnerable countries. Other donors, such as France, have pressed for greater incorporation of vulnerabilities directly into the PBA methodology. ${ }^{1}$ On the other side, many donors have argued that IDA's PBA already has an extensive number of exceptions that benefit fragile economies with significant needs. They are opposed to a further reduction of the importance of country performance in IDA's allocation system - arguing that development assistance is most effective in strong-performing countries with governments committed to good governance.

While these reform efforts differ in terms of mechanics, the philosophical thrust is the same that IDA should provide a greater percentage of its scarce resources to countries further down the development chain. Currently, IDA provides roughly two-thirds of its resources to the poorest countries (so-called IDA-only countries). Approximately half of IDA's money goes to SubSaharan Africa or Least-Developed Countries (LDCs). The aforementioned proposals ultimately would increase that share - particularly for countries with the greatest development challenges. The largest losers, on a relative basis, would be better performers and countries with higher incomes.

As the debate has re-surfaced in the context of the current IDA-16 replenishment negotiation, this paper examines how well IDA's existing PBA system actually addresses development needs and economic vulnerabilities. To achieve this, I examine how IDA allocations are distributed at each successive stage of the PBA methodology based upon a number of need and vulnerability measures. The paper is organized as follows. Section II briefly reviews a recent World Bank study that examined the linkages between IDA country allocations, performance, and development outcomes. Section III provides a step-by-step description of IDA's PBA methodology. Section IV examines how the different PBA steps and exceptions impact the distribution of IDA resources based upon country performance rating quartiles. Section V describes the development need and economic vulnerability proxies utilized in this study. Lastly, section VI examines how the different PBA steps and exceptions impact the distribution of IDA resources according to the distinct development need and vulnerability proxies.

\footnotetext{
${ }^{1}$ The French position has been influenced Patrick Guillaumont's recent work. See Guillaumont, Jeanneney, and Wagner (forthcoming) "Augmenting IDA Performance Based Allocation: The Vulnerability Issue".
} 


\section{ReCENT IDA Allocation Analysis}

In 2009, the World Bank published a paper entitled, "IDA's Performance Based Allocation and Development Results: An Update." Among other things, it explored the linkages between IDA's Country Policy and Institutional Assessment (CPIA), IDA allocations, and development outcomes between 1985 and 2006. In addition, it assessed trade-offs associated with shifting IDA's current performance-based allocation system to a development results-based system. The paper's key findings include:

- Performance and Development Outcome Linkage: Countries with high CPIA ratings, averaged over decades, achieved better human development and economic growth outcomes than those with relatively lower CPIA ratings.

- Correlation Between Performance and Human Development Measures: Average CPIA scores are highly correlated with several human development measures - including the UN Human Development Index, immunization rates, and GDP per capita growth rates.

- PBA and Development Needs Linkage: IDA's allocation system addresses development needs through several channels. Specifically, the paper finds that IDA's capping of allocations to large blend country increases the overall share of IDA resources allocated to Least Developed Countries (LDCs) from 21 percent to 48 percent.

This paper builds upon the previous World Bank paper by examining linkages between IDA's allocation methodology and a series of development need and economic vulnerability indicators. As noted, the World Bank paper examined correlations between CPIA scores and several measures of development needs. This paper expands the breadth of development need measures considered, including: (1) country progress on the Millennium Development Goals (MDGs); (2) absolute poverty (i.e., percentage of population earning less than $\$ 1.25$ a day); and (3) official development assistance (ODA) per capita.

\section{IDA PERformanCe-BaSed Allocation System Methodology}

For several decades, IDA has utilized a performance-based allocation system to determine country-by-country assistance volumes. Currently, each IDA-eligible country's allocation is based upon three key variables: (1) country performance rating; (2) population; and (3) gross national income (GNI) per capita. ${ }^{2}$ Over time, IDA shareholders have instituted a number of PBA exceptions to address distinct policy objectives (see steps 5-11 below). Given the system's increased complexity, this paper provides a brief overview of each sequential step of the PBA methodology. ${ }^{3}$

\footnotetext{
${ }^{2}$ The weighting of these three variables has evolved over time. See IDA (2007), IDA's Performance-Based Allocation System: Simplification of the Formula and Other Outstanding Issues.

${ }^{3}$ Also see Ravi Kanbur (2005), "Reforming the Formula: A Modest Proposal for Introducing Development Outcomes in IDA Allocation Procedures". In addition to examining the analytical underpinnings of IDA's allocation system, Kanbur proposes that it incorporate outcome variables.
} 
Country Performance Rating (Step \#1): The country performance rating is based upon two subcomponents - Country Policy and Institutional Assessment (CPIA) ratings and IDA project/program portfolio quality ratings. The CPIA assesses each IDA-eligible country's performance according to 16 policy and institutional quality criteria. ${ }^{4}$ These criteria are grouped into four equally weighted clusters: (A) economic management; (B) structural policies; (C) policies for social inclusion and equity; and (D) public sector management and institutions (commonly referred to as the "governance cluster"). See Appendix I for complete list of CPIA criteria. World Bank country staff collect this information through an annual questionnaire. ${ }^{5}$ Second, IDA staff utilize the World Bank's Annual Report on Portfolio Performance (ARPP) to determine each country's quality and management of IDA projects and programs.

\section{Country Performance Rating $=[0.24 *$ (Average Score of CPIA Clusters A-C $)]+[0.68 *$ CPIA Cluster D $]+[0.08 *$ Portfolio Quality $]$}

Country Allocation Score (Step \#2): IDA utilizes exponents to apply relative weightings to each of the three variables in the PBA formula. The country performance rating currently has an exponent of 5.0 and the population variable has an exponent of 1.0. Lastly, IDA applies an exponent of -0.125 to the GNI per capita variable. This is designed to modestly reduce IDA allocations for countries with relatively higher per capita income levels. In doing so, the PBA has a methodological favoring toward countries with greater needs (with income as a proxy measure).

IDA Country Allocation Score ${ }_{i}=\left(\right.$ Country performance rating ${ }_{i}^{5.0}$, Population $_{i}{ }^{1.0}$, GNI/capita $\left._{i}^{-0.125}\right)$

Relative Country Allocation Share (Step \#3): IDA then determines the relative allocation share for each country. The relative share is calculated by dividing each country's IDA allocation score by the total allocation score of all eligible countries.

$$
\text { Relative Country Allocation Share }_{i}=\frac{\text { IDA Country Allocation } \text { Score }_{i}}{\sum \text { IDA Country Allocation Scores }}
$$

Preliminary Country Allocation (Step \#4): IDA arrives at each country's preliminary allocation by multiplying its relative share by the total available IDA replenishment envelope.

IDA Country Allocation A $_{i}$ Country Allocation Relative Share ${ }_{i} *$ IDA Replenishment Envelope

Large Blend Cap Exception (Step \#5): IDA caps the total assistance volume provided to large blend countries. Without this cap, countries with very large populations, such as India, would receive the overwhelming majority of available IDA resources. ${ }^{6}$ During the IDA-15 replenishment period, IDA capped its assistance volumes to India and Pakistan at 18 percent of

\footnotetext{
${ }^{4}$ Country performance for each CPIA criteria is rated between 1 (lowest) and 6 (highest).

${ }^{5}$ To ensure CPIA rating consistency within and across regions, the World Bank extensively reviews and vets CPIA assessments for 12 "benchmark" countries.

${ }^{6}$ Without this exception, India would receive roughly 60 percent of all available IDA-15 replenishment resources.
} 
the total available envelope. Indications suggest that Vietnam also will be capped during the upcoming IDA-16 replenishment period. ${ }^{7}$

Base Allocation Exception (Step \#6): Every IDA-eligible country receives an annual base allocation. During the IDA-15 period, the base allocation was SDR 1.5 million (or SDR 4.5 million in total). Without this exception, most small countries (ex - Dominica and the Comoros) would receive inconsequential assistance volumes. For this IDA-15 period, the base allocation carved out roughly SDR 340 million (\$515 million) from the PBA - equivalent to roughly 1 percent of IDA's total resource envelope.

Post Conflict Exception (Step \#7): IDA provides a PBA exception for countries emerging from severe conflict that meet specific eligibility criteria ${ }^{89}$. This exception recognizes the acute recovery and reconstruction requirements of post-conflict countries. Under current IDA modalities, the exceptional post-conflict allocations can be provided for up to four years followed by a linear six-year transition back to the normal performance-based allocation process. ${ }^{10}$ Post-conflict allocations are still based on measures of country performance, which is captured by the Post-Conflict Performance Indicators (PCPI). The PCPI rating is the simple average of 12 customized variables. ${ }^{11}$ In practical terms, IDA simply substitutes qualifying country's CPIA scores with PCPI scores. During the transition period, IDA calculates the qualifying country's allocation based upon both the standard methodology (with CPIA scores) and exceptional post-conflict allocation methodology (with PCPI scores). Next, it calculates the differential between the two allocation outcomes, also called the country's post-conflict premium. If the country is in the transitional period, then IDA applies the phase-out factor ${ }^{12}$ to the difference, which produces the transition reduction. Fourth, it reduces the country's preliminary post-conflict allocation (again based on PCPI scores) by this transition reduction, which yields the country's final exceptional post-conflict allocation. Lastly, IDA re-allocates the transition reduction resources of qualifying post-conflict countries to all other IDA-only countries.

Reengaging Country Exception (Step \#8): Similar to the post-conflict exception, IDA can provide exceptional PBA allocations for countries reengaging with IDA after a prolonged period

\footnotetext{
${ }^{7}$ IDA projected that Vietnam would receive roughly SDR 2.5 billion during the IDA-15 period. This equals roughly 12 percent of total PBA allocated resources and 9 percent of total IDA-15 resource allocations (includes PBA exceptions).

${ }^{8}$ Eligibility for post-conflict exceptional allocations is based on: (1) the extent of human casualty caused by the conflict; (2) the proportion of the population that is internally displaced or in exile; or (3) the extent of physical destruction.

${ }^{9}$ Post-conflict countries currently include: Afghanistan, Angola, Burundi, Democratic Republic of Congo, Republic of Congo, Cote d'Ivoire, Eritrea, and Timor-Leste.

${ }^{10}$ The respective country returns to the normal PBA process after the sixth transition year.

${ }^{11}$ Post-Conflict Performance Indicator variables include: (1) public security; (2) reconciliation; (3) disarmament, demobilization, and reintegration of combatants; (4) management of inflation, external debt, and budget adequacy; (5) trade policy, foreign exchange rate and price regimes; (6) management and sustainability of post-conflict reconstruction program; (7) reintegration of displaced populations; (8) education; (9) health; (10) budget, financial management, and efficiency of resource mobilization; (11) re-establishing public administration and rules-based governance; and (12) transparency, accountability, and corruption in the public sector.

${ }^{12}$ IDA applies the following transition reduction factors: year 1 (one-seventh), year 2 (two-sevenths), year 3 (threesevenths), year 4 (four-sevenths), year 5 (five-sevenths), and year 6 (six-sevenths).
} 
of inactivity. ${ }^{13}$ These exceptional allocations may be provided for up to two years, followed by a linear three-year transition back to the normal performance-based allocation process. The transitional allocation is calculated in the same fashion as for post-conflict countries (as outlined above).

Grant Volume Reduction Exception (Step \#9): IDA then applies a volume reduction of 20 percent for countries' respective grant allocations. ${ }^{14}$ This reduction serves two objectives: (1) covering IDA's administrative fees that normally are met through loan charges; and (2) ensuring greater equity in terms of the net present value of IDA assistance with countries that are not eligible for grants. ${ }^{15}$ Of the 20 percent volume reduction, 11 percent is re-allocated to all IDAonly countries according to performance. ${ }^{16}$ During the IDA-15 period, IDA began utilizing the other 9 percent for non-concessional lending to blend countries with a per-capita income below the operational cutoff ${ }^{17}$ and an active IBRD borrowing program. The proceeds from these nonconcessional loans then are used to meet the administrative costs of IDA's grant projects and programs over time.

Multilateral Debt Relief Initiative Netting Out Exception (Step \#10): IDA also applies a separate volume reduction for countries eligible for the Multilateral Debt Relief Initiative (MDRI). More specifically, each qualifying countries' IDA allocation is reduced by the amount of annual MDRI debt service relief. As such, net assistance volumes (new assistance minus loan repayments) remain unchanged. Then, the volume reduction is re-allocated to all IDA-only countries including MDRI beneficiaries - according to performance. ${ }^{18}$ This so-called MDRI "netting out" is designed to ensure: (1) that incremental assistance due to debt relief is based on performance (not previous debt service obligations); and (2) equity with other IDA-only countries that have managed their external debt levels more prudently. Currently, shareholders are considering the possibility of eliminating the MDRI netting out exception in the context of the IDA-16 replenishment negotiations.

Post-Conflict and Reengaging Country Per Capita Cap Exception (Step \#11): IDA includes a cap on the level of annual per capita assistance provided to post-conflict and reengaging countries. The cap's size is determined by each country's performance rating - as measured by the PCPI rankings (see figure 1 below). As such, IDA provides a strong incentive to maximize performance. If a country's allocation exceeds the per capita cap, then IDA will impose a commensurate volume reduction. All volume reductions are then re-allocated to other IDAeligible countries.

\footnotetext{
${ }^{13}$ So-called reengaging countries include: Central African Republic, Haiti, and Togo.

${ }^{14}$ Under the World Bank/IMF debt sustainability framework, countries at a "high risk" of debt distress receive 100 percent of their IDA allocation in the form of grants. Countries at a "modest risk" of debt distress receive 50 percent of their IDA allocation in the form of grants.

${ }^{15}$ By illustration, an IDA credit has a grant element of roughly 65 percent. In NPV terms, it would be worth 35 percent less than an IDA grant with a grant element of 100 percent. Comparatively, IDA credits are still worth less even after the 20 percent grant volume reduction.

${ }^{16}$ IDA blend and hardened term countries are excluded from the re-allocation process.

${ }^{17}$ For FY10, IDA's operational income cutoff is \$1,135 (based on 2008 GNI per capita figures).

${ }^{18}$ IDA blend and hardened term countries are excluded from the re-allocation process.
} 


\title{
Figure 1 - Annual Per Capita Assistance Cap for Post-Conflict Countries ${ }^{19}$
}

\author{
Annual Per Capita Assistance Cap
}

\begin{tabular}{ccc} 
& \multicolumn{2}{c}{$($ in SDRs $)$} \\
\cline { 2 - 3 } $\begin{array}{c}\text { Post-Conflict Performance } \\
\text { Indicator Score }\end{array}$ & $\begin{array}{c}\text { Post-Conflict } \\
\text { Countries }\end{array}$ & $\begin{array}{c}\text { Reengaging } \\
\text { Countries }\end{array}$ \\
\hline$(2.5<$ PCPI < 3.0) & 6.0 & 3.0 \\
$(3.0<$ PCPI < 3.5) & 8.5 & 4.3 \\
$(3.5$ < PCPI < 4.0) & 11.9 & 6.0 \\
$(4.0$ < PCPI < 4.5) & 14.4 & 7.2 \\
$(4.5$ < PCPI < 5.0) & 17.0 & 8.5 \\
\hline
\end{tabular}

Per Capita Assistance Cap Exception (Step \#12): Lastly, IDA imposes a second, separate annual per capita assistance cap for all other countries (i.e., besides post-conflict countries). During the IDA-15 period, this cap was set at SDR 19.8 per capita per annum. Only a handful of small island countries are affected by this limit. Like the post-conflict assistance cap, any resulting volume reductions are re-allocated to all other IDA-eligible countries.

\section{IMPACT OF PBA SYSTEM EXCEPTIONS}

Given the multitude of PBA system exceptions, this paper examines just how performance-based IDA's allocation system really is. To do so, it examines the allocation distribution by country performance quartile at each stage of the PBA methodology (see appendix II). For reporting simplicity, several of the PBA methodology steps have been grouped together - such as the: (1) large blend cap and base allocation exceptions; and (2) post-conflict and reengaging country exceptions.

During the IDA-15 negotiations, World Bank staff published projected assistance allocations for all IDA-eligible countries during the ensuing replenishment period. ${ }^{20}$ However, this replenishment paper does not include projected IDA-15 allocations calculated at each successive stage of the PBA process. As a result, this paper has re-created the PBA using the above noted methodology to simulate the results. While every effort was made to ensure consistency with IDA's actual allocation system, undoubtedly there are country-specific variations compared to IDA's internally generated and authoritative figures. On average, final country-specific allocations differed by approximately 6 percent compared to those published publicly by World Bank staff.

Under the baseline scenario (no exceptions), the top performance quartile receives roughly 73 percent of the total IDA replenishment envelope. This figure is driven almost exclusively by India, which receives approximately 60 percent of the total resource envelope. In contrast, the worst performers receive only 2 percent of the total envelope. In per capita terms, IDA assistance volumes for the best performing countries are more than six times greater than the

\footnotetext{
${ }^{19}$ Source: IDA (2009), Implications of Extended Post-Conflict Facility Phase-Out

${ }^{20}$ See IDA (2007), IDA's Performance-Based Allocation System: Simplification of the Formula and Other Outstanding Issues
} 
level received by the bottom quartile (SDR 13 versus SDR 2). At this stage, the PBA system's heavy weighting on country performance remains intact.

However, the PBA system's purity quickly dissipates once the large blend cap and base allocation exceptions are instituted. Following these steps, the top performing quartile's share of IDA resources falls from 73 percent to roughly 41 percent. The cap on India's allocation is the key driver for this shift. ${ }^{21}$ In general, the reduction in India's allocation is distributed fairly evenly among the other three quartile groupings - with each group's allocation share increasing by over 100 percent. The bottom quartile's share increases from 2 percent to roughly 5 percent. In per capita terms, IDA assistance volumes for the best performing countries are only 41 percent higher than the level of the bottom quartile (SDR 7 versus SDR 5). ${ }^{22}$

The system's performance purity is further weakened by the post-conflict and reengaging country exceptions. Following these steps, the bottom performance quartile's share of IDA resources doubles from 5 percent to roughly 10 percent. This is not surprising given the poor performance profile of countries emerging from severe conflict or reengaging with IDA after an extended hiatus. ${ }^{23}$ During these stages, the other three quartiles all lose between 1 and 2 percent shares of the total IDA resource envelope. In per capita terms, the IDA assistance volumes for the best performing countries now are nearly 30 percent less than the level of the bottom quartile (SDR 7 versus SDR 10).

While the remaining PBA methodology steps (grant volume reduction, MDRI volume reduction, and per capita assistance caps) may significantly impact individual countries, their overall impact on quartile distributions is negligible.

Interestingly, the final distribution of IDA resources demonstrates very little linkage to performance levels when presented in quartile groupings (see figure 2 below). For example, the top performance quartile actually receives less in per capita terms than other quartiles. The largest beneficiary of these PBA system exceptions are the worst performers - whose share of total IDA resources increases by over 300 percent in per capita terms. Again, the allocation cap on India is the most important determinant. If India is excluded, the methodology performs very well at allocating resources according to country performance in per capita terms. ${ }^{24}$ If IDA's methodology has a somewhat uneven record of capturing performance, then perhaps it already does a decent job of capturing development needs and vulnerabilities.

\footnotetext{
${ }^{21}$ India's relative allocation share declines from roughly 60 percent of all IDA resources to 11 percent.

${ }^{22}$ If India is excluded, the allocation per capita differential between the top and bottom quartiles increases substantially - to nearly 500 percent (versus 41 percent with India).

${ }^{23}$ Every post-conflict or reengaging country is in the bottom quartile according to country performance ratings.

${ }^{24}$ If India is excluded, the top country performance quartile receives more than three times the IDA assistance in per capita terms compared to the bottom quartile (SDR 28 versus SDR 9).
} 


\section{Figure 2 - IDA Allocations by Country Performance Rating Quartile ${ }^{25}$}

\begin{tabular}{|c|c|c|c|c|c|c|c|c|}
\hline \multirow[b]{3}{*}{ Classification } & \multicolumn{4}{|c|}{ Exis ting Methodology (w/ India) } & \multicolumn{4}{|c|}{ Existing Methodology (w/out India) } \\
\hline & \multicolumn{2}{|c|}{$\begin{array}{c}\text { Baseline } \\
\text { (No Exceptions) }\end{array}$} & \multicolumn{2}{|c|}{ Final Allocation } & \multicolumn{2}{|c|}{$\begin{array}{c}\text { Baseline } \\
\text { (No Exceptions) }\end{array}$} & \multicolumn{2}{|c|}{ Final Allocation } \\
\hline & Gross & Per Capita & Gross & Per Capita & Gross & Per Capita & Gross & Per Capita \\
\hline \multicolumn{9}{|c|}{ Country Performance Rating } \\
\hline First Quartile & $73 \%$ & 13 & $39 \%$ & 7 & $33 \%$ & 14 & $31 \%$ & 28 \\
\hline Second Quartile & $9 \%$ & 10 & $19 \%$ & 20 & $23 \%$ & 10 & $22 \%$ & 20 \\
\hline Third Quartile & $15 \%$ & 6 & $33 \%$ & 13 & $38 \%$ & 6 & $37 \%$ & 13 \\
\hline Fourth Quartile & $2 \%$ & 2 & $9 \%$ & 9 & $5 \%$ & 2 & $10 \%$ & 9 \\
\hline
\end{tabular}

Source: IDA, author calculations

\section{Vulnerability ANd NeEdS Measures}

This paper measures the distribution of IDA resources according to several distinct indicators that proxy development needs and economic vulnerabilities. For development needs, I utilize the following proxies: (1) progress toward achieving the MDGs; (2) UN Human Development Index scores; (3) ODA per capita levels; (4) percentage of the population living on less than $\$ 1.25$ per day; and (5) GNI per capita. ${ }^{26}$ For vulnerability measures, this paper utilizes several shock indicators: (1) export volatility since 1990; (2) years of conflict since 1990; and (3) percentage of the population affected by natural disasters (i.e., floods, earthquakes, etc) since 1990. Each proxy indicator is explained in detail below. Importantly, these are purely indicative measures of development needs and economic vulnerabilities. Different measures, such as utilizing the percentage of the population living on less than $\$ 2$ per day (versus $\$ 1.25$ ), could impact the findings.

Development Need Measures: Building upon the previous World Bank study, this paper utilizes a number of indicators as proxies for development needs. The proxies can be categorized into several distinct groups, including: (1) access to core public services (health, education, and clean water); (2) income and absolute poverty prevalence; and (3) development assistance volumes.

MDG Progress Index: The MDG Progress Index is taken from the Center for Global Development's forthcoming dataset and working paper. ${ }^{27}$ It compares country's performance against required achievement trajectories for eight core MDG target indicators. ${ }^{28}$ This trajectory is based on linear, annualized rates of improvement for each respective MDG indicator. For

\footnotetext{
${ }^{25}$ Per capita assistance figures are represented in SDRs. With respect to the last two columns, the per capita allocations increase for all quartiles due to a simplification in the methodology. The calculations simply delete India's allocation and do not exclude India from the entire calculation. As such, the final allocations in per capita terms receive the redistributive benefit from India's cap.

${ }^{26}$ The previous World Bank study utilized the following proxies for development outcomes: (1) changes in UN Human Development Index scores; (2) changes in changes in the under-5 mortality rate; (3) changes in the immunization rate; and (4) real growth of GDP per capita.

${ }^{27}$ See Benjamin Leo and Julia Barmeier, "Who Are the MDG Trailblazers: A New MDG Progress Index", Center for Global Development (forthcoming).

${ }^{28}$ The indicators include: (1) proportion of population living under $\$ 1.25$ per day; (2) prevalence of underweight children under five years old; (3) primary education completion rate; (4) ratio of girls-to-boys in primary and secondary education; (5) child mortality rates; (6) maternal mortality ratios; (7) HIV/AIDS prevalence rate for ages $15-49$; and (8) proportion of population with access to improved water sources.
} 
example, to halve extreme poverty between 1990 and 2015, each country would need to achieve annualized reduction rates of 2 percent ( 50 percent divided by 25 years). By calculating each country's actual rate of improvement (or deterioration) during the available observation period, the index determines whether a country is above or below that MDG indicator achievement trajectory. For each indicator, those countries that are on par or above track receive a score of 1 and those below a score of 0 . To address criticisms that the MDG targets may be overly ambitious and unrealistic, the index assigns a score of 0.5 to countries that are within 25 percent of their target reduction rate. We have grouped the aggregated country index scores into quartiles. This Index can be viewed as both a measure of development progress and needs depending on whether the focus is on the worst or best performing countries. In addition, this is the only proxy indicator utilized in this paper that measures changes in country performance. The remaining development needs and economic vulnerability indicators measure absolute levels.

UN Human Development Index: The UN Human Development Index (HDI) attempts to capture three dimensions of a given country's social well-being: (1) population health and longevity (measured by life expectancy at birth); (2) education and knowledge (measured by the adult literacy rate and school enrollment ratios); and (3) standard of living (measured by gross domestic product per capita). The index produces a score ranging from 0 to 1.2008 data is available for all IDA-eligible countries except Kiribati and Zimbabwe. Given the HDI's inclusion of primary school enrollment ratios, we would expect at least a modest correlation with the MDG Progress Index.

Absolute Poverty Prevalence: To capture absolute poverty levels, this paper utilizes the percentage of the population living on less than $\$ 1.25$ a day. All data is from the 2009 UN Human Development Index database, which provides figures for 2008. The development literature would suggest a significant correlation with the MDG Progress Index due to the impact of extreme poverty levels on other social indicators, such as educational and health attainment. As noted above, the MDG Progress Index also includes this measure as one of the eight core MDG indicator targets.

Aid Volumes: Another needs measure is the level of total donor support provided to a given country. World Development Indicators data for 2008 is available for all IDA-eligible countries. Clearly, there will be endogeneity as IDA accounts for a significant percentage of aid flows to many low-income countries. Nonetheless, I include this measure to capture overall external assistance levels and to proxy financial needs. This will provide information on whether the prospective beneficiaries of the proposed PBA reforms already receive substantial amount of donor assistance (or lack thereof).

Income per Capita: Lastly, this paper includes GNI per capita as a separate proxy for development needs. World Bank data for 2008 is available for all IDA-eligible countries except Afghanistan and Zimbabwe.

Economic Vulnerability Measures: As noted previously, several IDA donors have pushed for the incorporation of vulnerability measures into IDA's allocation system. This paper utilizes several exogenous shock measures as proxies for economic vulnerability. The IMF defines an 
exogenous shock as an event beyond government control that has a significant negative economic impact. This would include: sharp decline in exports, conflicts, or natural disasters that have adverse balance of payments effects." 29 However, the IMF does not define what "significant economic impact" means in practice. As such, this paper utilizes a somewhat artificial threshold - that countries' export volumes fluctuated by 25 percent in a given year. The other determinants, such as natural disasters and conflict, are binary indicators.

Export Volatility: The export shocks data was calculated using World Development Indicators data for exports of goods and services as measured in constant 2000 U.S. Dollars. The time period covered is 1990 to 2008 . Volatility was measured as the frequency of annual changes (increase/decrease) of 25 percent or greater during the examined time period. After this, countries were categorized into respective quartiles - with the bottom quartile experiencing the greatest frequency in export shocks over time.

Prevalence of Conflict: The prevalence of conflict data was taken from the Uppsala Conflict Data Program \& International Peace Research Institute at Oslo (UCDP/PRIO) Armed Conflict dataset. Every year during the 1990-2008 time period, countries are coded with either a 1 or a 0 , representing the existence of conflict, or lack thereof. The conflict indicator was then tabulated as the total number of years that a respective country was at conflict during the examined time period. ${ }^{30}$ After this, countries were categorized into respective quartiles - with the bottom quartile experiencing the greatest prevalence of conflict over time. Importantly, the UCDP/PRIO armed conflict data differs significantly from IDA's eligibility requirements for exceptional post conflict allocations. Most importantly, IDA establishes a much higher bar with respect to the size of conflict and its impact on the nation's people and economy.

Natural Disasters: Data was gathered from the EM-DAT International Disaster Database run by the Centre for Research on the Epidemiology of Disasters (CRED). A disaster must meet one of the following criteria before being included in the database: (1) ten or more people reported killed; (2) 100 or more people reported affected; (3) a declaration of a state of emergency; or (4) a call for international assistance. This paper only considers natural disasters, including: droughts, earthquakes, epidemics, extreme temperatures, floods, insect infestations, storms, volcanoes, and wildfires. The measure was created by summing the "Total Affected Population" variable for each country over the 1991 to 2008 time period. EM-DAT classifies "Total Affected" as the sum of injured, homeless, and otherwise impacted people. ${ }^{31}$ The sum of total affected people was then taken as a percentage of country population (averaged over the time period). After this, countries were categorized into respective quartiles - with the bottom quartile experiencing the greatest impact from natural disasters over time.

Correlation Between Country Performance and Proxy Measures: Based on existing development literature, we would expect to find a significant correlation between countries' IDA performance ratings and many of the development need and economic vulnerability indicators. As expected, I

\footnotetext{
${ }^{29}$ IMF (2006), Guidance Note on the Exogenous Shocks Facility, page 3.

${ }^{30}$ Conflicts rated by the UCDP/PRIO dataset as either level 1 or level 2 intensity are included. Level 1 intensity corresponds to a "minor" conflict with between 25 and 999 battle-related deaths in a given year. Level 2 intensity corresponds to a "major" conflict with at least 1,000 battle-related deaths in a given year.

${ }^{31}$ Injured includes those who suffered physical injuries, trauma or an illness requiring medical treatment as a direct result of a disaster. Homeless is defined as people needing immediate shelter assistance. Affected are the number of people requiring immediate assistance during a period of emergency, including displaced or evacuated people.
} 
find a strong positive correlation between country performance and many of the development needs measures (both measured as country-specific point estimates), including MDG progress, HDI scores, ODA per capita, and GNI per capita (see appendix III). In addition, I find a negative correlation between the prevalence of extreme poverty and country performance levels as well as the other development needs indicators. IDA country performance ratings exhibit a negative correlation with all three economic vulnerability proxies. However, the correlation with export volatility and natural disasters is modest $(-0.122$ and -0.070$)$.

\section{IDA PBA OUTCOMES - HoW Well DOES IT AdDResS NEEDS AND Vulnerabilities?}

Similar to the examination of country allocations by performance ratings, I examine the distribution of country allocations based upon development needs and economic vulnerability measures at each stage of the PBA methodology. The summary results are reported for each measure separately below (see appendices VI and VII for additional details). With the exception of the MDG progress indicator, the bottom two quartiles receive over 60 percent of total available IDA resources for each of the development needs measures. The PBA exceptions also appear to redistribute resources to the most vulnerable countries. Largely due to the base allocation exception, countries that experience the greatest level of export volatility receive final IDA allocations roughly on par with countries with the lowest export volatility in per capita terms. The PBA methodology appears to compensate for higher vulnerability to natural disasters - as the bottom two quartiles receive nearly 60 percent of available IDA resources and nearly a third more in per capita assistance volumes than the least vulnerable countries.

Lastly, I find that countries that have spent the most time in conflict over the last 20 years receive only one-fifth the per capita assistance volumes compared to the least conflict-vulnerable countries. This is especially surprising given the PBA's post-conflict allocation exception. This contradiction appears to be driven purely by methodological issues. For example, the paper utilizes a much lower hurdle for defining conflicts and measures them in terms of their prevalence over time. In contrast, IDA utilizes a high eligibility burden for its post-conflict allocation exception in terms of economic and societal destruction. As such, a given country could become eligible for exceptional post-conflict allocations after a short and highly destructive conflict. This paper's methodology would not accurately capture that respective intensity.

MDG Progress Index: Under the baseline PBA scenario (no exceptions), countries that have achieved the greatest progress toward achieving the MDGs receive roughly 75 percent of total IDA resources while the worst performers receive about 9 percent. In per capita terms, the top performing countries on the MDGs receive near three times as much as the worst performing countries (SDR 13 versus SDR 5). Following the large blend cap and base allocation exceptions, the bottom quartile's share increases to 20 percent. It increases further to 23 percent after the post-conflict and reengaging country exceptions. As a result, the bottom quartile's allocation nearly triples in per capita terms (from SDR 5 to SDR 14). It receives twice as much in per capita terms compared to the best performers (SDR 14 versus SDR 7). 
UN Human Development Index: Under the baseline PBA scenario, countries with the highest HDI scores receive 8 percent of available IDA resources while the bottom quartile receives about 9 percent. Roughly two-thirds is allocated to the second quartile (due to India). After the large blend cap and base allocation exceptions, the bottom quartile's share increases to roughly 20 percent and the third quartile's share increases to 40 percent (from just under 20 percent). These relative shares remain more or less constant following the additional PBA exceptions. As such, countries below the median in terms of HDI scores receive over 60 percent of total available IDA resources. In per capita terms, the bottom quartile receives roughly 25 percent less than the highest performing countries (SDR 16 versus SDR 22).

Extreme Poverty Prevalence: Under the baseline scenario, countries with the greatest percentage of people living on less than $\$ 1.25$ per day receive just over 10 percent of all available IDA resources. Following the successive PBA exceptions, its final allocation share nearly triples to just below 30 percent. Taken together, the bottom two quartiles receive nearly 60 percent of available IDA resources. In per capita terms, the bottom two quartiles receive nearly the same assistance volumes compared to countries with the lowest prevalence of absolute poverty (SDR 16 versus SDR 19).

Aid Volumes: Following the first PBA step (no exceptions), countries that receive the lowest per capita aid volumes from all donor agencies receive over 80 percent of available IDA resources (again driven by India). Countries with the highest per capita aid volumes capture only 1 percent, which is largely due to the inclusion of a high number of island countries with small populations. The final allocation share for the bottom quartile remains high at 63 percent, which is somewhat surprising given the impact of the large blend cap on India's total allocation volume. This is explained in part by the offsetting increases for several post-conflict countries that receive lower per capita aid volumes, such as the DRC and Cote d'Ivoire. Taken together, the bottom two quartiles receive over 80 percent of IDA's resources. However, the bottom quartile receives only 40 percent as much IDA assistance in per capita terms compared to the top quartile (SDR 8 versus SDR 21).

GNI Per Capita: Under the baseline scenario, countries with the lowest income levels receive roughly 10 percent of IDA's resources. The wealthiest IDA-eligible countries receive only 1 percent, which is due to the concentration of small island countries. After the large blend cap and base allocation exceptions, the bottom quartile's share more than doubles to 23 percent while the richest country's share quadruples to roughly 4 percent (driven by the base allocation exception). These relative shares remain more or less constant following the additional PBA exceptions. As such, countries below the median in terms of income per capita receive over 60 percent of total available IDA resources. In per capita terms, the poorest countries receive the same level of IDA assistance as the wealthiest countries (SDR 17).

Export Volatility: Following the first PBA step (no exceptions), countries that have experienced the greatest export volatility over the last 20 years receive only 4 percent of total IDA resources. The second quartile receives over 80 percent (due to India). After the large blend cap and base allocation exceptions, the relative shares of the bottom two quartiles more than double to roughly 10 percent each. These relative shares remain more or less constant following the additional PBA exceptions. As such, countries below the median in terms of export volatility receive only 
20 percent of available IDA resources. However, they receive roughly the same level of assistance in per capita terms compared to countries with the lowest vulnerability to export volatility.

Conflict Prevalence: Under the baseline scenario, countries that have spent the most time in conflict over the last 20 years receive over 70 percent of all available IDA resources. ${ }^{32}$ Following the successive PBA exceptions, its final allocation share settles at 35 percent. Taken together, the bottom two quartiles receive roughly 55 percent of available IDA resources. In per capita terms, the bottom quartile receives about one-fifth the level of IDA assistance compared to countries with the lowest prevalence of conflict (SDR 5 versus SDR 25). When India is excluded, this ratio increases to roughly one-half (SDR 12 versus SDR 25).

Natural Disasters: Following the first PBA step (no exceptions), countries with the greatest vulnerability to natural disasters receive 23 percent of available IDA resources. By comparison, the top quartile receives roughly 17 percent. The bottom quartile's share remains more or less constant following the successive PBA exceptions. As such, the bottom two quartiles receive nearly 60 percent of total IDA resources and 30 percent higher in per capita terms compared to countries with the lowest vulnerability to natural disasters (SDR 17 versus SDR 13).

So How Well Does IDA Really Do?: The sections above provide a mind numbing list of figures illustrating the impact of IDA's PBA methodology on country allocations - as measured by a series of development needs and economic vulnerability indicators. Given the complexity involved, I also utilize two simple snapshots of just how well IDA's existing methodology performs at redistributing resources to neediest and more vulnerable countries. First, I apply a straightforward, and somewhat arbitrary, criterion - whether IDA allocations to the bottom quartile of countries are equal to or greater than the top quartile in per capita terms. Second, I compare per capita allocations to the bottom quartile of countries between the baseline and final PBA scenarios.

When viewed through the lens of allocation parity, IDA's performance is very modest (see figure 3 below). The PBA methodology's greatest redistributive impact is for countries with the lowest progress towards achieving the MDGs. For this measure, the bottom quartile receives twice as much as the top quartile in per capita terms - up from less than half under the PBA baseline scenario (i.e., no exceptions). Not surprisingly, IDA's methodology also does a decent job at allocating resources based upon GNI per capita levels - whereby, the bottom quartile receives the same assistance volume in per capita terms. For the remaining development needs and vulnerability measures, the PBA fails to provide per capita parity between the top and bottom quartiles of countries.

However, the litany of PBA exceptions clearly helps to redistribute resources to the neediest and most vulnerable countries in absolute terms. Per capita allocations to the bottom quartile of countries at least double between the baseline and final PBA scenarios for every need and vulnerability indicator. As noted previously, this is largely due to the cap on large blend countries and to a somewhat lesser degree by the post-conflict and reengaging country exceptions.

\footnotetext{
${ }^{32}$ Under the conflict measure dataset, India has experienced 19 years of conflict over the last twenty-five years.
} 
Figure 3 - IDA Allocations to Top and Bottom Country Quartiles, by Proxy Indicator ${ }^{33}$

\begin{tabular}{|c|c|c|c|c|}
\hline \multirow[b]{2}{*}{ Proxy Type } & \multirow[b]{2}{*}{ Proxy Indicator } & \multicolumn{2}{|c|}{$\begin{array}{c}\text { Bottom Quartile } \geq \text { Top } \\
\text { Quartile }\end{array}$} & \multirow{2}{*}{$\begin{array}{c}\text { Bottom Quartile Change } \\
\text { (Baseline and Final } \\
\text { Allocations) } \\
\text { Per Capita Increase }\end{array}$} \\
\hline & & Baseline & Final & \\
\hline Baseline & Country Performance Ratings & No & Yes & $310 \%$ \\
\hline \multirow{5}{*}{$\begin{array}{l}\text { Development } \\
\text { Needs }\end{array}$} & MDGProgress Index & No & Yes & $163 \%$ \\
\hline & UN Human Development Index & No & No & $143 \%$ \\
\hline & ODA Per Capita* & Yes & No & $121 \%$ \\
\hline & Population $<\$ 1.25 /$ Day & No & No & $124 \%$ \\
\hline & GNI Per Capita & Yes & Yes & $137 \%$ \\
\hline \multirow{3}{*}{$\begin{array}{c}\text { Economic } \\
\text { Vulnerabilities }\end{array}$} & Export Volatility & No & No & $109 \%$ \\
\hline & Conflict* & No & No & $105 \%$ \\
\hline & Natural Disasters* & Yes & No & $125 \%$ \\
\hline
\end{tabular}

\section{CONCLUSION}

Over the last few IDA replenishment periods, several large donors have pressed for reforms that would further increase the share of IDA resources allocated to countries with the greatest development needs and vulnerabilities. While the proposed reforms take different forms, the philosophical thrust is the same - push IDA's focus further down the development chain. Against this backdrop, this paper explores just how well IDA's existing PBA system actually addresses these issues. To achieve this, I examine how IDA allocations are distributed at each successive stage of the PBA methodology based upon a number of need and vulnerability measures. This examination includes both the relative share and absolute per capita allocations to the respective quartile groupings. Next, I apply two simple measures to gauge IDA's performance: (1) whether allocations to the bottom quartile of countries are equal to or greater than the top quartile in per capita terms; and (2) whether allocations to the bottom quartile increase between the baseline and final allocation scenarios. IDA's performance is very modest with respect to the relative share allocated to the neediest or most vulnerable countries. Of the eight proxy indicators examined, only two illustrate parity between final allocations to the bottom and top quartile of countries (MDG Progress Index and GNI per capita). However, the litany of PBA exceptions clearly helps to redistribute resources to the neediest and most vulnerable countries in absolute terms. Per capita allocations to the bottom quartile of countries more than doubles between the baseline and final PBA scenarios for every need and vulnerability indicator examined. As such, IDA has a mixed track record. Clearly, the existing system has several built-in biases to redistribute resources to the neediest and most vulnerable countries. However, these exceptions fall short from ensuring full parity that some IDA donors may wish to achieve. Given these inconclusive findings, the philosophical debate among key IDA donor governments likely will continue for the foreseeable future.

\footnotetext{
${ }^{33}$ Asterisk indicates that India has been excluded from the bottom quartile change column figures. This is due to the dampening impact on per capita allocation figures by IDA's cap on large blend countries.
} 


\section{Country Policy and Institutional Assessment Criteria}

A. Economic Management

1. Macroeconomic Management

2. Fiscal Policy

3. Debt Policy

B. Structural Policies

4. Trade

5. Financial Sector

6. Business Regulatory Environment

C. Policies for Social Inclusion/Equity

7. Gender Equality

8. Equity of Public Resource Use

9. Building Human Resources

10. Social Protection and Labor

11. Policies and Institutions for Environmental Sustainability

D. Public Sector Management and Institutions

12. Property Rights and Rule-based Governance

13. Quality of Budgetary and Financial Management

14. Efficiency of Revenue Mobilization

15. Quality of Public Administration

16. Transparency, Accountability, and Corruption in the Public Sector 
Impact of PBA Exceptions on IDA Allocations, by Country Performance Rating Quartile

\section{Existing Methodology (including India)}

\begin{tabular}{|c|c|c|c|c|c|c|c|c|c|c|c|c|}
\hline \multirow[b]{3}{*}{ Classification } & \multirow{2}{*}{\multicolumn{2}{|c|}{$\begin{array}{c}\text { Baseline (No } \\
\text { Exceptions) }\end{array}$}} & \multicolumn{10}{|c|}{ Performance-Based Allocation Exceptions } \\
\hline & & & \multicolumn{2}{|c|}{$\begin{array}{l}\text { IDA-Blend Cap \& } \\
\text { Base Allocation }\end{array}$} & \multicolumn{2}{|c|}{$\begin{array}{l}\text { Post-Conflict \& } \\
\text { Reengaging }\end{array}$} & \multicolumn{2}{|c|}{ Grant Adjustment } & \multicolumn{2}{|c|}{ MDRI Adjustment } & \multicolumn{2}{|c|}{$\begin{array}{l}\text { PCPI Adjustment } \\
\text { (FINAL) }\end{array}$} \\
\hline & Gross & Per Capita & Gross & Per Capita & Gross & Per Capita & Gross & Per Capita & Gross & Per Capita & Gross & Per Capita \\
\hline \multicolumn{13}{|c|}{ Country Performance Rating } \\
\hline First Quartile & $73 \%$ & 13 & $41 \%$ & 7 & $39 \%$ & 7 & $39 \%$ & 7 & $39 \%$ & 7 & $39 \%$ & 7 \\
\hline Second Quartile & $9 \%$ & 10 & $21 \%$ & 22 & $20 \%$ & 21 & $20 \%$ & 20 & $19 \%$ & 20 & $19 \%$ & 20 \\
\hline Third Quartile & $15 \%$ & 6 & $33 \%$ & 13 & $31 \%$ & 13 & $32 \%$ & 13 & $33 \%$ & 13 & $33 \%$ & 13 \\
\hline Fourth Quartile & $2 \%$ & 2 & $5 \%$ & 5 & $10 \%$ & 10 & $9 \%$ & 9 & $9 \%$ & 9 & $9 \%$ & 9 \\
\hline
\end{tabular}

\section{Existing Methodology (without India)}

\begin{tabular}{|c|c|c|c|c|c|c|c|c|c|c|c|c|}
\hline \multirow[b]{3}{*}{ Classification } & \multirow{2}{*}{\multicolumn{2}{|c|}{$\begin{array}{c}\text { Baseline (No } \\
\text { Exceptions) }\end{array}$}} & \multicolumn{10}{|c|}{ Performance-Based Allocation Exceptions } \\
\hline & & & \multicolumn{2}{|c|}{$\begin{array}{l}\text { IDA-Blend Cap \& } \\
\text { Base Allocation }\end{array}$} & \multicolumn{2}{|c|}{$\begin{array}{l}\text { Post-Conflict \& } \\
\text { Reengaging }\end{array}$} & \multicolumn{2}{|c|}{ Grant Adjustment } & \multicolumn{2}{|c|}{ MDRI Adjustment } & \multicolumn{2}{|c|}{$\begin{array}{l}\text { PCPI Adjus tment } \\
\text { (FINAL) }\end{array}$} \\
\hline & Gross & Per Capita & Gross & Per Capita & Gross & Per Capita & Gross & Per Capita & Gross & Per Capita & Gross & Per Capita \\
\hline \multicolumn{13}{|c|}{ Country Performance Rating } \\
\hline First Quartile & $33 \%$ & 14 & $34 \%$ & 31 & $32 \%$ & 29 & $32 \%$ & 29 & $31 \%$ & 28 & $31 \%$ & 28 \\
\hline Second Quartile & $23 \%$ & 10 & $24 \%$ & 22 & $22 \%$ & 21 & $22 \%$ & 20 & $22 \%$ & 20 & $22 \%$ & 20 \\
\hline Third Quartile & $38 \%$ & 6 & $37 \%$ & 13 & $35 \%$ & 13 & $36 \%$ & 13 & $37 \%$ & 13 & $37 \%$ & 13 \\
\hline Fourth Quartile & $5 \%$ & 2 & $6 \%$ & 5 & $11 \%$ & 10 & $10 \%$ & 9 & $10 \%$ & 9 & $10 \%$ & 9 \\
\hline
\end{tabular}


Correlation Analysis - Country Performance Ratings, Development Needs, and Vulnerability Measures

\section{Point Estimate Based Results}

\begin{tabular}{|c|c|c|c|c|c|c|c|c|c|}
\hline & \multicolumn{2}{|l|}{ Performance } & \multicolumn{3}{|c|}{ Development Needs } & \multicolumn{4}{|c|}{ Vulnerabilities (Shocks) } \\
\hline Proxy Measure & IDA Rating & MDGProgress & $\begin{array}{c}\text { Human } \\
\text { Development Index }\end{array}$ & ODA Per Capita & $\begin{array}{c}\text { Population < } \\
\$ 1.25 / \text { day }\end{array}$ & GNI Per Capita & Export Volatility & Conflict & Natural Disasters \\
\hline IDA Country Performance Rating & - & - & - & - & - & - & - & - & - \\
\hline MDG Progress & 0.355 & - & - & - & - & - & - & - & - \\
\hline Human Development Index & 0.526 & 0.254 & - & - & - & - & - & - & - \\
\hline ODA Per Capita & 0.219 & -0.131 & 0.375 & - & - & - & - & - & - \\
\hline Population $<\$ 1.25 /$ day & -0.313 & -0.734 & -0.734 & -0.232 & - & - & - & - & - \\
\hline GNI Per Capita & 0.441 & -0.096 & 0.743 & 0.526 & -0.531 & - & - & - & - \\
\hline Export Volatility & -0.122 & 0.032 & -0.153 & -0.165 & 0.049 & -0.105 & - & - & - \\
\hline Conflict & -0.346 & -0.079 & -0.346 & -0.335 & 0.188 & -0.248 & 0.257 & - & - \\
\hline Natural Disasters & -0.070 & 0.155 & -0.016 & -0.121 & -0.033 & -0.217 & 0.146 & 0.006 & - \\
\hline
\end{tabular}

\section{Quartile Based Results}

\begin{tabular}{|c|c|c|c|c|c|c|c|c|c|}
\hline \multicolumn{3}{|c|}{ Performance } & \multicolumn{3}{|c|}{ Development Needs } & \multicolumn{4}{|c|}{ Vulnerabilities (Shocks) } \\
\hline Proxy Measure & IDA Rating & MDG Progress & $\begin{array}{c}\text { Human } \\
\text { Development Index }\end{array}$ & ODA Per Capita & $\begin{array}{c}\text { Population < } \\
\$ 1.25 / \text { day }\end{array}$ & GNI Per Capita & Export Volatility & Conflict & Natural Disasters \\
\hline IDA Country Performance Rating & - & - & - & - & - & - & - & - & - \\
\hline MDGProgress & 0.309 & - & - & - & - & - & - & - & - \\
\hline Human Development Index & 0.402 & 0.262 & - & - & - & - & - & - & - \\
\hline ODA Per Capita & 0.364 & -0.172 & 0.284 & - & - & - & - & - & - \\
\hline Population $<\$ 1.25 /$ day & 0.314 & 0.193 & 0.623 & 0.241 & - & - & - & - & - \\
\hline GNI Per Capita & 0.359 & -0.073 & 0.678 & 0.467 & 0.604 & - & - & - & - \\
\hline Export Volatility & 0.060 & -0.023 & 0.116 & 0.078 & 0.144 & 0.040 & - & - & - \\
\hline Conflict & 0.405 & 0.075 & 0.439 & 0.512 & 0.287 & 0.370 & 0.375 & - & - \\
\hline Natural Disasters & -0.002 & -0.206 & -0.073 & 0.030 & 0.035 & 0.111 & 0.229 & 0.043 & - \\
\hline
\end{tabular}


Impact of PBA Exceptions on IDA Allocations, by Development Need Measure

Existing Methodology (including India)

\begin{tabular}{|c|c|c|c|c|c|c|c|c|c|c|c|c|c|}
\hline \multirow[b]{3}{*}{ Classification } & \multirow{2}{*}{\multicolumn{2}{|c|}{$\begin{array}{c}\text { Baseline (No } \\
\text { Exceptions) }\end{array}$}} & \multicolumn{10}{|c|}{ 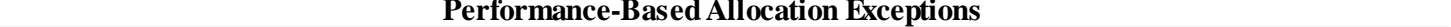 } & \multirow[b]{3}{*}{ Population } \\
\hline & & & \multicolumn{2}{|c|}{$\begin{array}{l}\text { IDA-Blend Cap \& } \\
\text { Base Allocation }\end{array}$} & \multicolumn{2}{|c|}{$\begin{array}{c}\text { Post-Conflict \& } \\
\text { Reengaging }\end{array}$} & \multicolumn{2}{|c|}{ Grant Adjustment } & \multicolumn{2}{|c|}{ MDRI Adjustment } & \multicolumn{2}{|c|}{$\begin{array}{l}\text { PCPI Adjus tment } \\
\text { (FINAL) }\end{array}$} & \\
\hline & Gross & Per Capita & Gross & Per Capita & Gross & Per Capita & Gross & Per Capita & Gross & Per Capita & Gross & Per Capita & \\
\hline \multicolumn{14}{|c|}{ Baseline (Country Performance Ratings) } \\
\hline First Quartile & $73 \%$ & 13 & $41 \%$ & 7 & $39 \%$ & 7 & $39 \%$ & 7 & $39 \%$ & 7 & $39 \%$ & 7 & 1,387 \\
\hline Second Quartile & $9 \%$ & 10 & $21 \%$ & 22 & $20 \%$ & 21 & $20 \%$ & 20 & $19 \%$ & 20 & $19 \%$ & 20 & 247 \\
\hline Third Quartile & $15 \%$ & 6 & $33 \%$ & 13 & $31 \%$ & 13 & $32 \%$ & 13 & $33 \%$ & 13 & $33 \%$ & 13 & 629 \\
\hline Fourth Quartile & $2 \%$ & 2 & $5 \%$ & 5 & $10 \%$ & 10 & $9 \%$ & 9 & $9 \%$ & 9 & $9 \%$ & 9 & 245 \\
\hline \multicolumn{14}{|l|}{ MDG Progress Index } \\
\hline First Quartile & $75 \%$ & 13 & $46 \%$ & 8 & $44 \%$ & 7 & $43 \%$ & 7 & $43 \%$ & 7 & $43 \%$ & 7 & 1,513 \\
\hline Second Quartile & $8 \%$ & 8 & $17 \%$ & 17 & $16 \%$ & 16 & $17 \%$ & 16 & $17 \%$ & 17 & $17 \%$ & 17 & 257 \\
\hline Third Quartile & $8 \%$ & 6 & $17 \%$ & 13 & $17 \%$ & 13 & $17 \%$ & 13 & $16 \%$ & 12 & $16 \%$ & 12 & 333 \\
\hline Fourth Quartile & $9 \%$ & 5 & $20 \%$ & 12 & $23 \%$ & 14 & $23 \%$ & 14 & $24 \%$ & 14 & $24 \%$ & 14 & 414 \\
\hline \multicolumn{14}{|c|}{ UN Human Development Index } \\
\hline First Quartile & $8 \%$ & 10 & $17 \%$ & 24 & $16 \%$ & 22 & $16 \%$ & 22 & $16 \%$ & 22 & $16 \%$ & 22 & 184 \\
\hline Second Quartile & $66 \%$ & 12 & $23 \%$ & 4 & $23 \%$ & 4 & $22 \%$ & 4 & $23 \%$ & 4 & $23 \%$ & 4 & 1,397 \\
\hline Third Quartile & $18 \%$ & 8 & $40 \%$ & 17 & $38 \%$ & 16 & $40 \%$ & 17 & $40 \%$ & 17 & $40 \%$ & 17 & 598 \\
\hline Fourth Quartile & $9 \%$ & 7 & $20 \%$ & 15 & $23 \%$ & 17 & $22 \%$ & 16 & $21 \%$ & 16 & $21 \%$ & 16 & 338 \\
\hline \multicolumn{14}{|l|}{ ODA Per Capita } \\
\hline First Quartile & $1 \%$ & 5 & $2 \%$ & 13 & $4 \%$ & 22 & $3 \%$ & 21 & $3 \%$ & 21 & $3 \%$ & 21 & 41 \\
\hline Second Quartile & $8 \%$ & 10 & $17 \%$ & 23 & $16 \%$ & 21 & $16 \%$ & 21 & $15 \%$ & 20 & $15 \%$ & 20 & 196 \\
\hline Third Quartile & $8 \%$ & 8 & $19 \%$ & 18 & $18 \%$ & 17 & $19 \%$ & 17 & $18 \%$ & 17 & $18 \%$ & 17 & 271 \\
\hline Fourth Quartile & $83 \%$ & 10 & $62 \%$ & 8 & $62 \%$ & 8 & $62 \%$ & 8 & $63 \%$ & 8 & $63 \%$ & 8 & 2,034 \\
\hline \multicolumn{14}{|l|}{ Population < \$1.25/Day } \\
\hline First Quartile & $5 \%$ & 9 & $11 \%$ & 20 & $10 \%$ & 19 & $10 \%$ & 19 & $10 \%$ & 19 & $10 \%$ & 19 & 130 \\
\hline Second Quartile & $15 \%$ & 9 & $32 \%$ & 18 & $32 \%$ & 18 & $31 \%$ & 17 & $31 \%$ & 17 & $31 \%$ & 17 & 441 \\
\hline Third Quartile & $68 \%$ & 12 & $30 \%$ & 5 & $30 \%$ & 5 & $30 \%$ & 5 & $30 \%$ & 5 & $30 \%$ & 5 & 1,433 \\
\hline Fourth Quartile & $12 \%$ & 7 & $28 \%$ & 16 & $29 \%$ & 16 & $28 \%$ & 16 & $29 \%$ & 16 & $29 \%$ & 16 & 438 \\
\hline \multicolumn{14}{|l|}{ GNI Per Capita } \\
\hline First Quartile & $1 \%$ & 7 & $4 \%$ & 17 & $4 \%$ & 18 & $4 \%$ & 18 & $4 \%$ & 17 & $4 \%$ & 17 & 52 \\
\hline Second Quartile & $71 \%$ & 11 & $34 \%$ & 5 & $34 \%$ & 5 & $34 \%$ & 5 & $34 \%$ & 5 & $34 \%$ & 5 & 1,639 \\
\hline Third Quartile & $18 \%$ & 9 & $39 \%$ & 21 & $37 \%$ & 20 & $38 \%$ & 20 & $38 \%$ & 20 & $38 \%$ & 20 & 472 \\
\hline Fourth Quartile & $10 \%$ & 7 & $23 \%$ & 16 & $26 \%$ & 18 & $24 \%$ & 17 & $24 \%$ & 17 & $24 \%$ & 17 & 354 \\
\hline
\end{tabular}




\section{Impact of PBA Exceptions on IDA Allocations, by Development Need Measure}

Existing Methodology (without India)

Performance-Based Allocation Exceptions

\begin{tabular}{|c|c|c|c|c|c|c|c|c|c|c|c|c|c|}
\hline \multirow[b]{3}{*}{ Classification } & \multirow{2}{*}{\multicolumn{2}{|c|}{$\begin{array}{l}\text { Baseline (No } \\
\text { Exceptions) }\end{array}$}} & & \multirow[b]{3}{*}{ Population } \\
\hline & & & \multicolumn{2}{|c|}{$\begin{array}{l}\text { IDA-Blend Cap \& } \\
\text { Base Allocation }\end{array}$} & \multicolumn{2}{|c|}{$\begin{array}{l}\text { Post-Conflict \& } \\
\text { Reengaging }\end{array}$} & \multicolumn{2}{|c|}{ Grant Adjustment } & \multicolumn{2}{|c|}{ MDRI Adjus tment } & \multicolumn{2}{|c|}{$\begin{array}{l}\text { PCPI Adjus tment } \\
\text { (FINAL) }\end{array}$} & \\
\hline & Gross & Per Capita & Gross & Per Capita & Gross & Per Capita & Gross & Per Capita & Gross & Per Capita & Gross & Per Capita & \\
\hline \multicolumn{14}{|c|}{ Baseline (Country Performance Ratings) } \\
\hline First Quartile & $33 \%$ & 14 & $34 \%$ & 31 & $32 \%$ & 29 & $32 \%$ & 29 & $31 \%$ & 28 & $31 \%$ & 28 & 247 \\
\hline Second Quartile & $23 \%$ & 10 & $24 \%$ & 22 & $22 \%$ & 21 & $22 \%$ & 20 & $22 \%$ & 20 & $22 \%$ & 20 & 247 \\
\hline Third Quartile & $38 \%$ & 6 & $37 \%$ & 13 & $35 \%$ & 13 & $36 \%$ & 13 & $37 \%$ & 13 & $37 \%$ & 13 & 629 \\
\hline Fourth Quartile & $5 \%$ & 2 & $6 \%$ & 5 & $11 \%$ & 10 & $10 \%$ & 9 & $10 \%$ & 9 & $10 \%$ & 9 & 245 \\
\hline \multicolumn{14}{|l|}{ MDG Progress Index } \\
\hline First Quartile & $39 \%$ & 11 & $39 \%$ & 24 & $37 \%$ & 22 & $36 \%$ & 22 & $36 \%$ & 22 & $36 \%$ & 22 & 373 \\
\hline Second Quartile & $19 \%$ & 8 & $19 \%$ & 17 & $18 \%$ & 16 & $19 \%$ & 16 & $19 \%$ & 17 & $19 \%$ & 17 & 257 \\
\hline Third Quartile & $20 \%$ & 6 & $19 \%$ & 13 & $19 \%$ & 13 & $19 \%$ & 13 & $18 \%$ & 12 & $18 \%$ & 12 & 333 \\
\hline Fourth Quartile & $22 \%$ & 5 & $23 \%$ & 12 & $26 \%$ & 14 & $26 \%$ & 14 & $27 \%$ & 14 & $27 \%$ & 14 & 414 \\
\hline \multicolumn{14}{|c|}{ UN Human Development Index } \\
\hline First Quartile & $19 \%$ & 10 & $19 \%$ & 24 & $18 \%$ & 22 & $18 \%$ & 22 & $18 \%$ & 22 & $18 \%$ & 22 & 184 \\
\hline Second Quartile & $15 \%$ & 6 & $14 \%$ & 12 & $13 \%$ & 12 & $13 \%$ & 11 & $13 \%$ & 11 & $13 \%$ & 11 & 257 \\
\hline Third Quartile & $45 \%$ & 8 & $45 \%$ & 17 & $43 \%$ & 16 & $45 \%$ & 17 & $45 \%$ & 17 & $45 \%$ & 17 & 598 \\
\hline Fourth Quartile & $21 \%$ & 7 & $22 \%$ & 15 & $25 \%$ & 17 & $24 \%$ & 16 & $24 \%$ & 16 & $24 \%$ & 16 & 338 \\
\hline \multicolumn{14}{|l|}{ ODA Per Capita } \\
\hline First Quartile & $2 \%$ & 5 & $2 \%$ & 13 & $4 \%$ & 22 & $4 \%$ & 21 & $4 \%$ & 21 & $4 \%$ & 21 & 41 \\
\hline Second Quartile & $19 \%$ & 10 & $19 \%$ & 23 & $18 \%$ & 21 & $18 \%$ & 21 & $17 \%$ & 20 & $17 \%$ & 20 & 196 \\
\hline Third Quartile & $21 \%$ & 8 & $21 \%$ & 18 & $21 \%$ & 17 & $21 \%$ & 17 & $20 \%$ & 17 & $20 \%$ & 17 & 271 \\
\hline Fourth Quartile & $58 \%$ & 7 & $57 \%$ & 14 & $57 \%$ & 14 & $57 \%$ & 14 & $59 \%$ & 15 & $59 \%$ & 15 & 894 \\
\hline \multicolumn{14}{|l|}{ Population < \$1.25/Day } \\
\hline First Quartile & $11 \%$ & 9 & $12 \%$ & 20 & $11 \%$ & 19 & $11 \%$ & 19 & $11 \%$ & 19 & $11 \%$ & 19 & 130 \\
\hline Second Quartile & $37 \%$ & 9 & $36 \%$ & 18 & $36 \%$ & 18 & $35 \%$ & 17 & $35 \%$ & 17 & $35 \%$ & 17 & 441 \\
\hline Third Quartile & $21 \%$ & 7 & $21 \%$ & 16 & $21 \%$ & 15 & $21 \%$ & 16 & $22 \%$ & 16 & $22 \%$ & 16 & 293 \\
\hline Fourth Quartile & $31 \%$ & 7 & $31 \%$ & 16 & $32 \%$ & 16 & $32 \%$ & 16 & $32 \%$ & 16 & $32 \%$ & 16 & 438 \\
\hline \multicolumn{14}{|l|}{ GNI Per Capita } \\
\hline First Quartile & $4 \%$ & 7 & $4 \%$ & 17 & $4 \%$ & 18 & $4 \%$ & 18 & $4 \%$ & 17 & $4 \%$ & 17 & 52 \\
\hline Second Quartile & $28 \%$ & 6 & $26 \%$ & 12 & $26 \%$ & 12 & $26 \%$ & 12 & $26 \%$ & 12 & $26 \%$ & 12 & 499 \\
\hline Third Quartile & $44 \%$ & 9 & $44 \%$ & 21 & $41 \%$ & 20 & $42 \%$ & 20 & $43 \%$ & 20 & $43 \%$ & 20 & 472 \\
\hline Fourth Quartile & $25 \%$ & 7 & $26 \%$ & 16 & $29 \%$ & 18 & $27 \%$ & 17 & $27 \%$ & 17 & $27 \%$ & 17 & 354 \\
\hline
\end{tabular}


Impact of PBA Exceptions on IDA Allocations, by Economic Vulnerability Measure

Existing Methodology (including India)

Performance-Based Allocation Exceptions

\begin{tabular}{|c|c|c|c|c|c|c|c|c|c|c|c|c|c|}
\hline \multirow[b]{3}{*}{ Classification } & \multirow{2}{*}{\multicolumn{2}{|c|}{$\begin{array}{c}\text { Baseline (No } \\
\text { Exceptions) }\end{array}$}} & & \multirow[b]{3}{*}{ Population } \\
\hline & & & \multicolumn{2}{|c|}{$\begin{array}{c}\text { IDA-Blend Cap \& Base } \\
\text { Allocation }\end{array}$} & \multicolumn{2}{|c|}{$\begin{array}{l}\text { Post-Conflict \& } \\
\text { Reengaging }\end{array}$} & \multicolumn{2}{|c|}{ Grant Adjustment } & \multicolumn{2}{|c|}{ MDRI Adjus tment } & \multicolumn{2}{|c|}{$\begin{array}{c}\text { PCPI Adjustment } \\
\text { (FINAL) }\end{array}$} & \\
\hline & Gross & Per Capita & Gross & Per Capita & Gross & Per Capita & Gross & Per Capita & Gross & Per Capita & Gross & Per Capita & \\
\hline \multicolumn{14}{|c|}{ Baseline (Country Performance Ratings) } \\
\hline First Quartile & $73 \%$ & 13 & $41 \%$ & 7 & $39 \%$ & 7 & $39 \%$ & 7 & $39 \%$ & 7 & $39 \%$ & 7 & 1,387 \\
\hline Second Quartile & $9 \%$ & 10 & $21 \%$ & 22 & $20 \%$ & 21 & $20 \%$ & 20 & $19 \%$ & 20 & $19 \%$ & 20 & 247 \\
\hline Third Quartile & $15 \%$ & 6 & $33 \%$ & 13 & $31 \%$ & 13 & $32 \%$ & 13 & $33 \%$ & 13 & $33 \%$ & 13 & 629 \\
\hline Fourth Quartile & $2 \%$ & 2 & $5 \%$ & 5 & $10 \%$ & 10 & $9 \%$ & 9 & $9 \%$ & 9 & $9 \%$ & 9 & 245 \\
\hline \multicolumn{14}{|l|}{ Export Volatility } \\
\hline First Quartile & $8 \%$ & 8 & $20 \%$ & 18 & $20 \%$ & 18 & $20 \%$ & 18 & $19 \%$ & 17 & $19 \%$ & 17 & 240 \\
\hline Second Quartile & $83 \%$ & 12 & $59 \%$ & 7 & $60 \%$ & 7 & $60 \%$ & 7 & $61 \%$ & 8 & $61 \%$ & 8 & 1,724 \\
\hline Third Quartile & $4 \%$ & 8 & $11 \%$ & 18 & $10 \%$ & 17 & $10 \%$ & 16 & $10 \%$ & 16 & $10 \%$ & 16 & 129 \\
\hline Fourth Quartile & $4 \%$ & 7 & $10 \%$ & 15 & $10 \%$ & 14 & $10 \%$ & 14 & $10 \%$ & 14 & $10 \%$ & 14 & 153 \\
\hline \multicolumn{14}{|l|}{ Conflict } \\
\hline First Quartile & $15 \%$ & 12 & $33 \%$ & 28 & $31 \%$ & 26 & $31 \%$ & 26 & $30 \%$ & 25 & $33 \%$ & 25 & 304 \\
\hline Second Quartile & $5 \%$ & 6 & $11 \%$ & 13 & $10 \%$ & 12 & $11 \%$ & 13 & $11 \%$ & 13 & $12 \%$ & 13 & 212 \\
\hline Third Quartile & $8 \%$ & 7 & $18 \%$ & 15 & $18 \%$ & 15 & $18 \%$ & 15 & $18 \%$ & 15 & $20 \%$ & 15 & 308 \\
\hline Fourth Quartile & $72 \%$ & 11 & $38 \%$ & 6 & $41 \%$ & 6 & $40 \%$ & 6 & $40 \%$ & 6 & $35 \%$ & 5 & 1,693 \\
\hline \multicolumn{14}{|l|}{ Natural Disasters } \\
\hline First Quartile & $7 \%$ & 6 & $16 \%$ & 13 & $16 \%$ & 13 & $16 \%$ & 12 & $17 \%$ & 13 & $17 \%$ & 13 & 316 \\
\hline Second Quartile & $9 \%$ & 11 & $20 \%$ & 24 & $21 \%$ & 24 & $21 \%$ & 24 & $20 \%$ & 23 & $20 \%$ & 23 & 212 \\
\hline Third Quartile & $15 \%$ & 8 & $32 \%$ & 17 & $31 \%$ & 16 & $31 \%$ & 16 & $31 \%$ & 16 & $31 \%$ & 16 & 475 \\
\hline Fourth Quartile & $69 \%$ & 12 & $32 \%$ & 6 & $32 \%$ & 5 & $32 \%$ & 5 & $33 \%$ & 6 & $33 \%$ & 6 & 1,448 \\
\hline
\end{tabular}




\section{Impact of PBA Exceptions on IDA Allocations, by Economic Vulnerability Measure}

Existing Methodology (without India)

Performance-Based Allocation Exceptions

\begin{tabular}{|c|c|c|c|c|c|c|c|c|c|c|c|c|c|}
\hline \multirow[b]{3}{*}{ Classification } & & & \multicolumn{10}{|c|}{ Pertormance-Based Allocation Exceptions } & \multirow[b]{3}{*}{ Population } \\
\hline & \multicolumn{2}{|c|}{$\begin{array}{c}\text { Baseline (No } \\
\text { Exceptions) }\end{array}$} & \multicolumn{2}{|c|}{$\begin{array}{c}\text { IDA-Blend Cap \& Base } \\
\text { Allocation }\end{array}$} & \multicolumn{2}{|c|}{$\begin{array}{l}\text { Post-Conflict \& } \\
\text { Reengaging }\end{array}$} & \multicolumn{2}{|c|}{ Grant Adjustment } & \multicolumn{2}{|c|}{ MDRI Adjustment } & \multicolumn{2}{|c|}{$\begin{array}{l}\text { PCPI Adjustment } \\
\text { (FINAL) }\end{array}$} & \\
\hline & Gross & Per Capita & Gross & Per Capita & Gross & Per Capita & Gross & Per Capita & Gross & Per Capita & Gross & Per Capita & \\
\hline \multicolumn{14}{|c|}{ Baseline (Country Performance Ratings) } \\
\hline First Quartile & $33 \%$ & 14 & $34 \%$ & 31 & $32 \%$ & 29 & $32 \%$ & 29 & $31 \%$ & 28 & $31 \%$ & 28 & 247 \\
\hline Second Quartile & $23 \%$ & 10 & $24 \%$ & 22 & $22 \%$ & 21 & $22 \%$ & 20 & $22 \%$ & 20 & $22 \%$ & 20 & 247 \\
\hline Third Quartile & $38 \%$ & 6 & $37 \%$ & 13 & $35 \%$ & 13 & $36 \%$ & 13 & $37 \%$ & 13 & $37 \%$ & 13 & 629 \\
\hline Fourth Quartile & $5 \%$ & 2 & $6 \%$ & 5 & $11 \%$ & 10 & $10 \%$ & 9 & $10 \%$ & 9 & $10 \%$ & 9 & 245 \\
\hline \multicolumn{14}{|l|}{ Export Volatility } \\
\hline First Quartile & $22 \%$ & 8 & $23 \%$ & 18 & $23 \%$ & 18 & $23 \%$ & 18 & $22 \%$ & 17 & $22 \%$ & 17 & 240 \\
\hline Second Quartile & $54 \%$ & 8 & $53 \%$ & 17 & $54 \%$ & 17 & $54 \%$ & 17 & $55 \%$ & 18 & $55 \%$ & 18 & 584 \\
\hline Third Quartile & $12 \%$ & 8 & $12 \%$ & 18 & $12 \%$ & 17 & $11 \%$ & 16 & $11 \%$ & 16 & $11 \%$ & 16 & 129 \\
\hline Fourth Quartile & $12 \%$ & 7 & $12 \%$ & 15 & $12 \%$ & 14 & $12 \%$ & 14 & $11 \%$ & 14 & $11 \%$ & 14 & 153 \\
\hline \multicolumn{14}{|l|}{ Conflict } \\
\hline First Quartile & $36 \%$ & 12 & $37 \%$ & 28 & $35 \%$ & 26 & $35 \%$ & 26 & $34 \%$ & 25 & $35 \%$ & 25 & 304 \\
\hline Second Quartile & $12 \%$ & 6 & $12 \%$ & 13 & $12 \%$ & 12 & $12 \%$ & 13 & $13 \%$ & 13 & $13 \%$ & 13 & 212 \\
\hline Third Quartile & $20 \%$ & 7 & $20 \%$ & 15 & $20 \%$ & 15 & $20 \%$ & 15 & $21 \%$ & 15 & $21 \%$ & 15 & 308 \\
\hline Fourth Quartile & $32 \%$ & 6 & $30 \%$ & 12 & $34 \%$ & 14 & $32 \%$ & 13 & $32 \%$ & 13 & $31 \%$ & 12 & 553 \\
\hline \multicolumn{14}{|l|}{ Natural Disasters } \\
\hline First Quartile & $17 \%$ & 6 & $18 \%$ & 13 & $18 \%$ & 13 & $18 \%$ & 12 & $19 \%$ & 13 & $19 \%$ & 13 & 316 \\
\hline Second Quartile & $22 \%$ & 11 & $23 \%$ & 24 & $23 \%$ & 24 & $23 \%$ & 24 & $22 \%$ & 23 & $22 \%$ & 23 & 212 \\
\hline Third Quartile & $38 \%$ & 8 & $36 \%$ & 17 & $35 \%$ & 16 & $35 \%$ & 16 & $35 \%$ & 16 & $35 \%$ & 16 & 475 \\
\hline Fourth Quartile & $23 \%$ & 8 & $24 \%$ & 17 & $23 \%$ & 16 & $23 \%$ & 16 & $24 \%$ & 17 & $24 \%$ & 17 & 308 \\
\hline
\end{tabular}

